\title{
RESEARCH
}

\section{An Updated National Profile of Curriculum Committees in Pharmacy Education}

\author{
Jean T. Carter, PhD, PharmD, ${ }^{a}$ Staci Hemmer, MA, PharmD, ${ }^{\text {a }}$ Melissa S. Medina, EdD, ${ }^{\text {b,c }}$ Lauren Sinko, \\ PharmD, ${ }^{\mathrm{b}}$ JoLaine R. Draugalis, $\mathrm{PhD}^{\mathrm{b}}$ \\ ${ }^{\text {a }}$ University of Montana, Skaggs School of Pharmacy, Missoula, Montana \\ ${ }^{\mathrm{b}}$ University of Oklahoma College of Pharmacy, Oklahoma City, Oklahoma \\ ${ }^{\mathrm{c}}$ Associate Editor, American Journal of Pharmaceutical Education, Arlington, Virginia
}

Corresponding Author: Melissa S. Medina, University of Oklahoma, College of Pharmacy, PO Box 26901, 1110 N. Stonewall, CPB 225, Oklahoma City, OK 73190. Tel: 405-271-6484. Email: melissa-medina@ouhsc.edu

Submitted May 25, 2021; accepted November 10, 2021; ePublished November 2021

Objective. To assess how U.S. schools and colleges of pharmacy curriculum committees' responsibilities, structure, functions, charges, and activities have evolved since 2011.

Methods. A total of 133 fully-accredited schools and colleges of pharmacy were included in the survey. Data collection occurred between March and September 2020, and survey questions pertained to the academic year (19-20). Data were collected on committee membership, leadership, functions, and charges. New questions explored ties to assessment and Standards 2016. Analysis included descriptive statistics and comparisons to the 2011 survey results.

Results. Response rate was 80\%; one partial response was excluded from analysis. Most (93\%) schools and colleges rely on a curriculum committee to provide curriculum oversight. Faculty and students remain the most frequent types of members but there has been an increase in the number of committees with members from other areas including experiential programs, staff, directors, librarians, and pharmacy residents. Committee charges have increased beyond the traditional curriculum planning, mapping, and review to include newer tasks (eg, EPAs, IPEs, PPCP, co-curriculum, certificates). Primary responsibility for various assessment activities is shared by both committees in $1 / 3$ of the institutions.

Conclusion. Curriculum committees remain a key part of pharmacy education but continue to evolve to meet their responsibility for new and increasing numbers of charges and finding ways to communicate and share duties with their assessment counterparts. Having clear guidance for the $\mathrm{CC}$ and reducing frequency of scheduled work to ensure the $\mathrm{CC}$ will be able to address new challenges as they emerge are recommended.

Keywords: curriculum, curriculum committee, assessment committee, survey

\section{INTRODUCTION}

Pharmacy education is constantly evolving to incorporate new standards and innovations. Curriculum committees (CCs) within schools/colleges of pharmacy (S/COP) are tasked with implementing these changes. ${ }^{1,2}$ An initial survey of CCs occurred in 1995, followed by one in 2011., ${ }^{1,2}$ Since 2011, many changes to pharmacy education have occurred including the 2013 revision of the Center for the Advancement of Pharmacy Education (CAPE) outcomes that were expanded to include the affective domain. ${ }^{3}$ These CAPE outcomes were then integrated into the Accreditation Council for Pharmacy Education (ACPE) revised accreditation standards (Standards 2016) as Standards one to four. ${ }^{3,4}$ Standards 2016 and its guidance document also increased emphasis on interprofessional education (IPE), Pharmacist's Patient Care Process (PPCP), and co-curricular activities. ${ }^{4,5}$ The pharmacy academy has promoted additional curricular considerations such as entrustable professional activities (EPAs). Standards 2016 also made the Pharmacy Curriculum Outcomes Assessment (PCOA) a mandatory standardized assessment for students to complete prior to advanced pharmacy practice experiences (APPEs). In addition, the role of curriculum assessment has been slowly migrating to assessment committees with some curriculum committees still actively involved in curricular assessment. ${ }^{6,7}$

This survey is the third in a series of studies used to describe S/COP CCs. In 1995, CCs focused on the implementation of the PharmD program and efforts shifted to the integration and addition of courses. ${ }^{1}$ In 2011 , CCs responded to new ACPE standards by adding experiential content, developing curriculum competencies and assessing student outcomes. ${ }^{2}$ Recommendations based on the 2011 results were to optimize the CC membership diversity and length of service. The goal of this third study is to assess how the responsibilities, structure, functions, charges, and activities of CCs in U.S. S/COP have evolved since 2011. 


\section{METHODS}

The study used survey methods to gather information from U.S. S/COP regarding their curriculum oversight practices. The sampling frame consisted of 133 programs fully accredited during the data collection period. Individuals at each of the colleges most familiar with CCs were identified through websites, AACP rosters, or by administrators at their institution. Each potential respondent received an invitation email with an attached cover letter and copy of the questionnaire; this was followed by up to three reminders. The data collection period was March through August 2020. Respondents could use either an online Qualtrics (Qualtrics.com, Provo, UT) questionnaire or a Microsoft Word (Microsoft Corporation, Redmond, WA) file they could return via email. The study design was approved by both campus institutional review boards (IRBs).

The questionnaire was based on the instrument used in the 1995 and 2011 surveys of curriculum committees. ${ }^{1,2}$ The items were reviewed and updated with some response options changed or deleted and several new items related to Standards 2016 added. ${ }^{4,5}$ The questionnaire contained 32 items that were mostly close-ended with several open-ended questions. Response options included selecting one or more choices, options using a rating scale with 5-levels (1as the lowest rating), open-ended fill in responses, and an "other" option for most questions. It explored the structure and membership of the committee, its charges and functions, curriculum oversight responsibilities, and CC association with assessment committees. Respondents were asked to recall and describe their institution's CC during the 2019-20 academic year.

Responses were compiled into a Microsoft Excel (Microsoft Corporation, Redmond, WA) spreadsheet. Descriptive statistics produced frequencies, ranges, and means. The S/COPs public/private status and years since established and differences between 2011 and 2020 data were compared statistically using Chi Squared tests of proportions and means. ${ }^{8}$ Significance for statistical tests was set $a$ priori at $p<0.05$ per test.

\section{RESULTS}

Response rate was $80 \%$ which was adjusted to $79 \%$ after removing one partially completed questionnaire from analysis. Responders and non-responders had similar institutional characteristics: public institutions (51\% and $48 \%, p=$ $.79)$, private institutions ( $49 \%$ and $52 \%, p=.79)$, and mean (SD) years since established were $70.6(56.3)$ and $70.58(61)$, $p>.99$ ), respectively.

Fifty eight percent of programs were organized by traditional quarter- or semester-long courses, $29 \%$ offered a combination of traditional and shorter block-style courses, and $12 \%$ used only block courses, which is a significant increase from $4 \%$ using block courses in 2011 $(p=.049)$. Ninety-three percent of S/COPs charged a CC with curricular oversight, sometimes in collaboration with the assessment committee, academic affairs office, or an academic dean (3\%). Rarely, oversight was the sole responsibility of an academic affairs committee (3\%) or a curriculum office (1\%).

The CC was the only entity to address curricular topics for $43 \%$ of S/COP which is down from $70 \%$ in 2011 ( $p$ $<.001)$. Less frequently, administration $(34 \%)$ and assessment committees or directors $(13 \%)$ shared responsibility for curricular matters with the $\mathrm{CC}$. For a small fraction of S/COPs, some curricular topics were addressed by committees that focused on specific courses or course sequences (6\%), ad hoc curriculum review or revision committees (4\%), IPE committees $(5 \%)$, co-curricular committees $(4 \%)$, the experiential education office $(3 \%)$, and the full faculty $(2 \%)$. Individual S/COPs listed other entities that address curricular topics: student services, university curriculum committee, continuing professional development coordinator, and committees focused on cultural diversity, teaching, or student wellbeing.

\section{Curriculum Committee Structure}

Committees were led by a single chair $(80 \%)$, two co-chairs or vice chairs $(14 \%)$, which is an increase from $1 \%$ in $2011(p=.001)$, or a single vice chair $(1 \%)$. Faculty most frequently served in the leadership position $(91 \%)$ which is down from $99 \%$ in $2011(p=.016)$, followed by assistant and associate deans $(7 \%)$ or combinations of a chair and an academic affairs administrator $(2 \%)$. Some of the faculty chairs $(9 \%)$ also had additional administrative roles, usually in academic affairs (no statistically significant decrease from 2011).

Appointments to CC chair were made by either the Dean (57\%), members of the CC (32\%) or by assistant/associate deans (9\%). The deans' appointments were often guided by input from executive committees or department heads. Two percent of the committee chairs were elected by faculty. The chairs served a mean (SD) of 2.5 (2.88) years with terms ranging from less than one to 13 years which did not significantly differ from $2011(p=.274)$

The CC size ranged from seven to 27 with a mean (SD) of 14.5 (4.22) members, which is a significant increase from the 2011 mean (SD) of 10.6 (3.8) ( $p<.001)$. Most committees had faculty (100\%), students (94\%), and assistant or associate deans $(92 \%)$ as members, which was not significantly different from 2011 . There was a significant increase in other types of members from $39 \%$ in 2011 to $54 \%$ in $2020(p=.041)$. Voting status varied by member type with faculty 
and students having the highest percentages of voting members and these percentages have not changed from 2011. Department chairs with voting status did decrease from $80 \%$ to $53 \%(p=.026)$. Table 1 lists committee members by type and voting status. The length of service for committee members ranged from one to six years, with some colleges allowing a second term or an indefinite appointment. Reappointments occurred annually (31\%), every two years (24\%), every three years $(29 \%)$ or six years $(14 \%)$. The CC members or chairs served different term lengths at some S/COPs.

Like CC chairs, faculty members were most frequently appointed by their dean (87\%) usually upon being recommended by executive committees, assessment deans, or department chairs (76\%). At some S/COPs, faculty members were selected by their peers as a whole or as a department $(16 \%)$ or through self-nomination, input by a Committee-on-Committees, or recommendation of the CC chair (12\%). Faculty members were selected based on department affiliation (91\%), willingness to serve (75\%), workload (74\%), area of expertise (41\%), years of service (38\%) and rank or tenure status $(22 \%)$. Three programs also considered core course coordination, campus location, and current or prior service on the committee in their selections.

Student member selection was based on response to a call to participate (53\%), appointment by the Dean (34\%), nomination by classmates $(25 \%)$, invitation by committee members $(18 \%)$ or faculty members $(3 \%)$. Student members were also elected by their classmates or selected by their student council, class officers, class advisor, or student affairs director at a few schools.

Preferred qualities in committee members were commitment to the program's mission (68\%), objectivity (46\%), educational experience (33\%), and vision (18\%). These have been the top four qualities selected in both prior surveys. Other qualities identified were interest in teaching (17\%), leadership (12\%), willingness to be engaged and actively participate $(6 \%)$, dependability $(1 \%)$, teamwork skills $(1 \%)$, and an understanding of educational theory $(1 \%)$.

Most committees met monthly (72\%) or every two weeks (19\%). The use of monthly meetings significantly increased from $33 \%$ in $2011(p<.001)$, while the use of every two-week schedules was unchanged. Some met at least once a semester $(5 \%)$ or weekly $(3 \%)$. Six percent of the committees with regularly scheduled meetings indicated they also had additional meetings as needed. The use of as needed meetings only instead of scheduled meetings dropped from $27 \%$ in 2011 to $2 \%$ in $2020(p<.001)$.

\section{Functions of Committee}

Annual charges were assigned to $89 \%$ of the CCs during the 2019-20 academic year. Charges were received from the dean or associate dean (75\%), the CC (39\%), via standing charges (38\%), or the Executive Committee (5\%). CCs often received charges from multiple sources (44\%).

Current charges for the CCs included reviewing or mapping the curriculum (55\%); adding or revising courses (51\%); evaluating courses $(51 \%)$, and reviewing or restructuring committee policies and practices (36\%). Rates were similar to 2011 levels for curriculum review and course evaluation, but higher in 2011 for adding/revising courses $(70 \%, p$ $=.009)$ and restructuring policies $(2 \%, p<.001)$. Table 2 lists the top charges for the current and future academic year.

While charges indicated specific foci for the year, CCs generally have these responsibilities: reviewing proposals for new courses (96\%); ensuring curriculum meets ACPE standards (95\%); reviewing and revising entire curriculum (91\%); performing systematic reviews of didactic courses (87\%); reviewing the timing/placement of courses within the curriculum ( $82 \%$ ); ensuring new information is added to the curriculum $(74 \%)$; ensuring integration of topics across courses (64\%); conducting systematic reviews of the experiential courses $(63 \%)$, reviewing credit hours $(57 \%)$; and changing content (53\%). These frequencies are similar to the 2011 list of CC functions. Fewer CCs were also responsible for promoting innovative teaching (37\%), organizing the co-curriculum $(29 \%)$, handling student and faculty curriculum grievances $(27 \%$ and $25 \%$, respectively), and monitoring the use of exams $(8 \%)$. These functions were not measured in 2011. A small number of CCs were also approving and reviewing certificate or dual degree programs, updating and reviewing the curriculum map and reviewing course policies such as remediation or attendance.

Course changes that would prompt CC involvement were credit hour adjustments (96\%), elective course proposals $(92 \%)$, changes to pre-requisites (77\%), and addition $(61 \%)$ or deletion (64\%) of curricular content. For some $\mathrm{CCs}$, a $10-25 \%$ change in course content required the CC's involvement. Committees were also involved when changes affected instructional methods (34\%), assessment methods $(12 \%)$, course objectives $(12 \%)$ course coordinator assignment $(12 \%)$ or when the change would impact other courses or mapped content $(11 \%)$. A few CCs were responsible for reviewing and approving changes to a course name, focus, and catalog information.

In AY19-20, CCs were implementing curriculum revisions (42\%), conducting full curriculum reviews $(21 \%)$, planning revisions (14\%), planning to do a major review in the next five years (14\%), or had no plans to review their curriculum within the next five years $(7 \%)$.

CCs performed systematic and scheduled reviews of individual pharmacy courses every three years (21\%), every four years $(19 \%)$, annually $(16 \%)$, every five years $(5 \%)$, every two years $(4 \%)$ or using a variable schedule depending on 
type of course (10\%). The rest did their individual course reviews on an as-needed basis $(25 \%)$. There were significant increases from 2011 to 2020 in the systematic reviews of required lecture-based courses $(63 \%$ to $100 \%, p<.001)$; required lab courses $(57 \%$ to $99 \%, p<.001)$, and required experiential IPPE/APPE courses $(35 \%$ to $66 \%, p<.001)$. Review of elective courses by $38 \%$ of CCs was not significantly different from 2011 . Two CCs were reviewing all courses as part of implementation of a new curriculum while another was monitoring tracks within their program.

Data used for course reviews came from syllabi (88\%); student evaluations (68\%); student exam scores (55\%); contributions to student outcomes (46\%); formative, high-stakes assessments (40\%); assignments (36\%); feedback from IPPE/APPE preceptors (34\%); standardized assessments (31\%); and faculty peer course evaluations (18\%). Some CCs also used faculty self-evaluations and reflections ( $8 \%$ ), overall course grades $(6 \%)$, and reviews of lecture and assessment materials (5\%). Two S/COPs had faculty review their own course evaluations from peers and students instead of asking the CC to do it. Individual CCs reported using published sources such as white papers, ${ }^{9}$ survey results from pharmacy organizations, ${ }^{10}$ and accreditation standards. ${ }^{4}$

On a five-point scale, mean (SD) faculty conservatism and reluctance to change was 2.8 (1.2) which was rated once again as the greatest barrier to CC effectiveness followed by a mean (SD) reliance on "quick-fixes" and not longterm change of 2.2 (1.2). In 2011, the mean (SD) for faculty conservatism was 3.9 (1.2) followed by departmental autonomy mean (SD) rating of 2.8 (1.3). Table 3 compares the average (SD) ratings for 2011 and 2020 including statistically significant reductions in departmental autonomy, lack of interdisciplinary collaboration, and lack of authority for the $\mathrm{CC}$ as barriers to effectiveness.

\section{CAPE Outcomes}

Most (97\%) respondents linked their student outcomes to the CAPE domains through mapping to (39\%), adoption of $(31 \%)$, or integration with $(25 \%)$ the CAPE domains. Two respondents $(2 \%)$ used multiple methods to align student outcomes with CAPE domains. The process of mapping student outcomes to Standards 2016 domains was an ongoing process for many curriculum committees with varying degrees of completion as shown in Table 4 . Forty percent had a nearly completed map of their curriculum to the 15 domains in Standards 1, 2, 3, and 4 plus PPCP, teamwork, and cocurriculum elements, while another $16 \%$ were more than halfway done mapping to all categories. Twenty-eight percent of the committees were near-completion for mapping most but not all of the domains and elements (ie, 12-15 domains completed) and $23 \%$ had fully mapped to fewer than four of the domains. Two CCs indicated no intention of mapping their curriculum to any of the domains.

\section{Working with Assessment Committee}

The most common mode of communication between the curriculum committee and those responsible for assessment was to have a member of one committee attend the meetings of the other group (86\%). Of these, $57 \%$ of the $\mathrm{S} / \mathrm{COPs}$ sent a representative to each other committee's meetings, $39 \%$ sent an assessment member to the curriculum meeting, and 3\% sent a curriculum representative to assessment meetings. Other communication modes between curriculum and assessment were holding a separate meeting between designated members of the two oversight groups, usually the chairs (46\%), an exchange of meeting minutes $(13 \%)$, an administrator that links both groups $(8 \%)$, or joint meetings between the full membership of the two groups (7\%). No mechanism of communication was reported when a single group was responsible for both curriculum and assessment matters $(3 \%)$ or because the assessment oversight group did not exist or was newly formed $(2 \%)$.

The CCs continued to be involved in many curriculum assessment activities within S/COPs, although this was most often done in collaboration with the assessment committee (Table 5). Assessment of interprofessional education (IPE) was the only area where more CCs $(42 \%)$ had primary responsibility than shared responsibility (38\%). More than half of CCs had responsibility for assessments related to content or structure of the program such as co-curriculum, EPAs, student course/instructor evaluations, and APPE readiness, but this responsibility was commonly shared with the assessment committee. Conversely, fewer than half of the CCs were involved in outcomes-oriented assessments such as high-stakes exams, licensing exams, graduating student surveys, AACP quality surveys ${ }^{10}$, or the Pharmacy Curriculum Outcomes Assessment (PCOA). ${ }^{11}$ Here the primary responsibility was more frequently assigned to the assessment committee (33-66\%) or shared (22-39\%). Other entities such as assessment or academic affairs deans or offices were infrequently assigned primary responsibility for assessment activities.

\section{DISCUSSION}

The structure of the committee has continued to increase in size and diversity of membership compared to the 2011 study. ${ }^{2}$ Reasons for this shift in membership may be due in part to the increasing need for the committee to work with other services and departments on campus to fulfill accreditation standards. Length of time as a member was 
unchanged from 2011 although increasing it was a recommendation. Faculty continue to be the most common choice for $\mathrm{CC}$ chair and methods for identifying and assigning chairs and members to the CC remain largely unchanged; however, the use of co-chairs has increased. Reasons for this increase are not clear but there may be efforts to share what appears to be an increasing workload or perhaps help smooth transitions in leadership if such appointments are staggered.

More CCs reported having regularly scheduled meetings with fewer meetings on an as needed basis; the use of monthly meetings has increased. Reasons for the shift to monthly meetings could be the increased number of functions CCs have and the need to have scheduled meetings so the members of the larger, diverse CCs can plan on set meeting dates and times.

It is evident from the lists of charges and functions that CCs are addressing more curricular issues than in previous years. Some of this expanded workload can be tied to efforts to meet accreditation requirements; some is related to the increased attention on specific areas within the Academy such as assessing competency achievement and incorporating EPAs. ${ }^{12-14}$ Surprisingly, committees were not as focused on addressing interprofessional education or co-curriculum, given their importance in the ACPE standards. It is possible co-curriculum is being addressed by another entity in the college since it is technically not part of the curriculum, and interprofessional education may be organized at a higher level on campus.

Faculty reluctance to change has remained consistently the largest barrier to effectiveness across all three survey studies. ${ }^{1,2}$ Of the nine new barriers identified in the current study, lack of member engagement and lack of curriculum guidelines stood out. The lack of member engagement is a surprising barrier given the sizable workload required to systematically review courses. Perhaps not all of the CC members are making equitable contributions, which could be one explanation. A lack of curriculum guidelines is concerning given the importance of promoting consistency in curricular delivery and assessment, but this may be changing as updating curriculum committee guidelines was one of the charges listed by respondents.

Finding half of the CCs have not completely mapped their curriculum to all of the domains is surprising considering the ACPE standards were published five years ago and the CAPE outcomes were published eight years ago. ${ }^{3,4}$ It is noted that a lack of progress in mapping of certain domains or the additional elements does not mean the college lacks coverage of them in its curriculum. The question is whether the $\mathrm{CC}$ has too large a workload and that is leading to delays in completing tasks such as this or if the CC needs better guidance on how to approach such tasks.

Consistent with the 2011 study, assessment committees remain separate from CCs at many S/COPs. As a result, identifying who is responsible for a given assessment and how the committees communicate are additional considerations for CCs. A closer inspection reveals CCs still tended to take primary responsibility for internal assessments that most directly relate to the curriculum structure and processes whereas responsibility for more outcomes-oriented, external assessments tended to be primarily with the assessment committees. These findings are consistent with a recent survey in which half of the S/COPs surveyed estimated $20 \%$ or more of the CCs time is devoted to assessment activities. ${ }^{7}$

Based on the survey results and the knowledge that the CAPE outcomes and ACPE standards will be revised in the next few years, which will likely impact the CC work, it may be a good time to ensure the CC has clear guidance regarding its functions and charges, review membership and member involvement in the CC's work, and find ways to reduce frequency of scheduled reviews and other work to ensure there is time for addressing new curricular issues.

There are potential limitations to this study that are similar to the previous 2011 study. ${ }^{2}$ First, this study involved survey research and the CC chair was the only responder to the survey. It is assumed that the CC chairs answered the survey questions honestly and accurately and that their answers were reflective of the entire committee. However, it is possible their recollections may differ from their committee members. A second limitation is that some questions required the CC chair to recall information from the past year, which may have introduced recall bias. Relatedly, the study questionnaire was distributed to the CC chairs during the early stages of the COVID-19 pandemic and the chairs may have been under stress, which may have also affected their recall. Finally, although the research team evaluated all study questions and options for clarity, they may have been misinterpreted by the $\mathrm{CC}$ chair.

\section{CONCLUSIONS}

Curriculum committees remain a key part of pharmacy education but continue to evolve to meet their responsibility for new and increasing numbers of charges and finding ways to communicate and share duties with their assessment counterparts. Having clear guidance for the $\mathrm{CC}$ and reducing frequency of scheduled work to ensure the $\mathrm{CC}$ will be able to address new challenges as they emerge is recommended.

\section{REFERENCES}

1. Carter JT, Draugalis JR. The curriculum committee: a national profile of U.S. colleges of pharmacy. Am J Pharm Educ. 1995;59(1):27-34. 
2. Carter JT, Draugalis JR, Bruce SP, Gonyeau MR. The role of curriculum committees in pharmacy education. Am J Pharm Educ. 2011;75(8):154.

3. Medina MS, Plaza CM, Stowe CD, et al. Center for the Advancement of Pharmacy Education 2013 educational outcomes. Am J Pharm Educ. 2013;77(8):162

4. Accreditation Council for Pharmacy Education. Accreditation standards and key elements for the professional program leading to the doctor of pharmacy degree. Standards 2016. https://www.acpeaccredit.org/pdf/Standards2016FINAL.pdf. Accessed May 18, 2021.

5. American Council for Pharmacy Education. Guidance for Standards 2016. 2015. https://www.acpeaccredit.org/pdf/GuidanceforStandards2016FINAL.pdf . Accessed May 18, 2021.

6. Dintzner MR, Ried LD. Where we are now: A 2015 snapshot of assessment personnel and practices in US Schools and Colleges of pharmacy. Curr Pharm Teach Learn. 2016;8(3):299-304.

7. Rudolph MJ, Lee KC, Assemi M, et al. Surveying the current landscape of assessment structures and resources in US schools and colleges of pharmacy. Curr Pharm Teach Learn. 2019;11(2):117-128.

8. MedCalc Tests on summarized data. Comparison of Proportions online calculator using "N-1" Chi-squared test (https://www.medcalc.org/calc/comparison_of_proportions.php) and Comparison of Means online calculator (https://www.medcalc.org/calc/comparison_of_means.php). Accessed May 18, 2021.

9. Flannery AH, Soric MM, Benavides S, et al. 2019 update to the American College of Clinical Pharmacy pharmacotherapy didactic curriculum toolkit. J Am Coll Clin Pharm. 2020;3:455-464.

10. Meny L, Seiferlein M, Chen AMH, et al. National survey of the administration and evaluation of the AACP Curriculum Quality Surveys. Am J Pharm Educ. 2021;85(3):Article 8045.

11. Medina MS, Neely S, Draugalis JR. Predicting pharmacy curriculum outcomes assessment performance using admissions, curricular, demographics, PCOA Pre-Test, and preparation data. Am J Pharm Educ. 2019; 83(10): Article 7526.

12. Medina MS. Does competency-based education have a role in US academic pharmacy? Pharmacy. 2017;5(1):13.

13. Haines ST, Pittenger AL, Stolte SK, et al. Core entrustable professional activities for new pharmacy graduates. $A m J$ Pharm Educ. 2017;81(1):Article S2.

14. Pittenger AL, Copeland DA, Lacroix MM, et al. Report of the 2016-17 Academic Affairs Standing Committee: Entrustable professional activities implementation roadmap. Am J Pharm Educ. 2017;81(5):Article S4.

Table 1. Number of Curriculum Committees with One or More Members in each Category by Total and by Voting Status Subsets in 2011 and 2020

\begin{tabular}{|c|c|c|c|c|c|c|}
\hline $\begin{array}{l}\text { Member Category (Total } \\
\text { Committees) }\end{array}$ & $\begin{array}{c}2020 \text { Total } \\
(\mathrm{n}=105)\end{array}$ & $\begin{array}{l}2020 \text { Voting } \\
\text { Subset }^{\mathrm{a}}\end{array}$ & $\begin{array}{l}2011 \text { Total } \\
(\mathrm{n}=83)\end{array}$ & $\begin{array}{c}2011 \\
\text { Voting } \\
\text { Subset }^{\mathrm{a}}\end{array}$ & $\begin{array}{c}p \text { Value } \\
\text { Totals }\end{array}$ & $\begin{array}{l}p \text { Value } \\
\text { Voting } \\
\text { Subsets }\end{array}$ \\
\hline Deans & 6 & 0 & 9 & 1 & .279 & $>.99$ \\
\hline Assistant/Associate Deans & 97 & 42 & 71 & 35 & .156 & .531 \\
\hline Department chairs/Unit head & 43 & 23 & 30 & 24 & .551 & .026 \\
\hline $\begin{array}{l}\text { Faculty members, all ranks, } \\
\text { type }\end{array}$ & 105 & 105 & 83 & 83 & $>.99$ & $>.99$ \\
\hline Students & 100 & 70 & 74 & 60 & .162 & .114 \\
\hline Alumni & 26 & 18 & 19 & 14 & .864 & $>.99$ \\
\hline Non-faculty practitioners & 36 & 24 & 36 & 27 & .228 & .605 \\
\hline Other $^{\mathrm{b}}$ & 57 & 25 & 32 & 15 & .041 & .827 \\
\hline
\end{tabular}

a. Voting subset numbers based on total number of schools and colleges in that category in that year

b. Other includes staff, experiential programs, coordinators and directors, librarians, fellows and pharmacy residents, faculty from other campus pathways, medical school faculty and a community member

c. Chi Squared / Fisher exact tests were used to calculate $p$ values between the two years ${ }^{8}$ 
Table 2. Percent of Curriculum Committees with Charges in Current AY19-20 and Future Academic Year Grouped by Category

\begin{tabular}{cc} 
Current & Future Charges \\
AY19-20 & AY 20-21 \\
$(\mathbf{n}=\mathbf{8 7})$ & $(\mathrm{n}=\mathbf{1 0 4})$ \\
\hline
\end{tabular}

Reviewing, Mapping, Revising, Evaluating Focused

$\begin{array}{lr}\text { Reviewing or mapping the curriculum } & 55\end{array}$

42

Adding or revising courses

Evaluating courses (syllabi, instructional methods, topics)

41

Reviewing / restructuring committee policies and practices

53

Mapping curricular outcomes to external sources ${ }^{\mathrm{a}}$

10

$---b^{-b}$

Curriculum revision

Reviewing elective courses

Reviewing or implementing EPAs

Reviewing or promoting specialty tracks, certifications, or dual degrees

Reviewing the experiential curriculum

Reviewing or implementing co-curriculum

Reviewing or implementing interprofessional education (IPE) activities

Developing elective courses

$\begin{array}{lc}51 & 41 \\ 51 & 53 \\ 36 & 10 \\ 26 & ---\mathrm{b} \\ 18 & 3\end{array}$

$18 \quad 30$

$16 \quad 34$

$14 \longrightarrow 2$

$14---b$

$10 \quad 11$

$10 \longrightarrow 15$

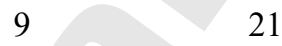

Committee Administration Focused

Collaborating with assessment committee to find areas for improvement

Preparing a report for faculty or administration

Restructuring committee membership

Reviewing remediation issues related to the curriculum

Select next year's charges

Student Outcomes, Assessment, and Evaluation Focused

Developing curriculum competency (student outcomes)

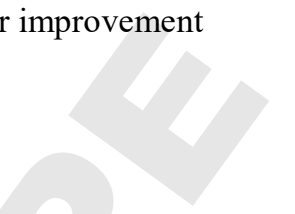

Assessing curriculum competency (student outcomes)

Overseeing the pre-pharmacy curriculum

Assess technology unitization and needs

Evaluate APPE Sites

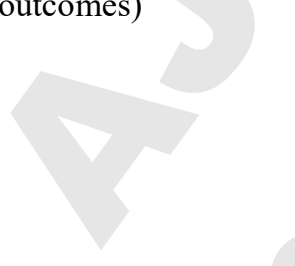

$\underline{\text { Instruction Focused }}$

Promoting innovative teaching strategies

$16 \quad 43$

Consulting external sources for best practices in pharmacy education

Managing the PPCP content in the curriculum

Promoting diversity, social justice, antiracism in the curriculum

Improve online teaching in context of pandemic

Accreditation Focused

Performing tasks related to ACPE self-study and site visit

Other Focused

Other

Did not list specific charges

a. External sources listed by respondents included "Standards 2016, ${ }^{4}$ " "NAPLEX blueprint,"4 and "ACCP Toolkit""

b. Future response options did not list this specific item

c. Other current charges included set academic calendar, determine class schedule for Fall 2020, select teacher of the year, implement disease state workgroup, reduce academic dishonesty, respond to curriculum issues referred by the dean, implement college-wide and university-wide curricular initiatives, identify issues created by curricular revision, promote interdivisional collaboration, review prerequisites/corequisites, evaluate change of semester credit hours, evaluate recommendation for Bachelors in Pharmaceutical Sciences (BSPS) program, implement foundations for professional development,

d. Other future charges included BSPS program, incorporate assessment data into existing comprehensive curriculum review, improve integration of course content throughout the curriculum, and develop proactive tools to identify poor performers 
Table 3. Pharmacy Curriculum Committee Mean (SD) Ratings ${ }^{\mathrm{a}}$ of Barriers to Committee Effectiveness for Surveys in 2011 and 2020

\begin{tabular}{|c|c|c|c|}
\hline Barriers & $\begin{array}{c}2020 \\
(n=104)^{b}\end{array}$ & $\begin{array}{c}2011 \\
(\mathbf{n}=83)^{b}\end{array}$ & $p$ value \\
\hline Faculty conservatism and reluctance to change & $2.8(1.2)$ & $3.0(1.2)$ & .259 \\
\hline Reliance on "quick fix" and not long-term change & $2.2(1.2)$ & $2.4(1.2)$ & .259 \\
\hline Ineffective college-wide planning & $2.1(1.2)$ & $2.4(1.3)$ & .103 \\
\hline Failure to build consensus & $2.1(1.2)$ & $2.2(1.0)$ & .543 \\
\hline Lack of group member engagement ${ }^{\mathrm{c}}$ & $2.1(1.1)$ & --- & $\mathrm{n} / \mathrm{a}$ \\
\hline Lack of interdisciplinary collaboration & $2.0(1.0)$ & $2.4(1.2)$ & .014 \\
\hline Lack of curriculum guidelines & $2.0(1.2)$ & --- & $\mathrm{n} / \mathrm{a}$ \\
\hline Lack of authority of curriculum committee ${ }^{c}$ & $1.9(1.2)$ & $2.3(1.2)$ & .025 \\
\hline Different agendas for committee and administration & $1.9(1.2)$ & $2.1(1.2)$ & .259 \\
\hline Departmental autonomy & $1.9(1.1)$ & $2.8(1.3)$ & $<.001$ \\
\hline Poor communication with Assessment Committee/group ${ }^{c}$ & $1.9(1.1)$ & --- & $\mathrm{n} / \mathrm{a}$ \\
\hline General lack of interest in the curriculum by the faculty ${ }^{c}$ & $1.9(1.0)$ & & $\mathrm{n} / \mathrm{a}$ \\
\hline $\begin{array}{l}\text { Ideas for development or change appear to come out of thin air (no } \\
\text { based) }\end{array}$ & $1.9(1.0)$ & --- & $\mathrm{n} / \mathrm{a}$ \\
\hline Lack of student performance / outcomes data ${ }^{c}$ & $1.9(1.0)$ & --- & $\mathrm{n} / \mathrm{a}$ \\
\hline Failure to involve departments early in the process ${ }^{\mathrm{c}}$ & $1.7(0.9)$ & $1.9(0.9)$ & .133 \\
\hline Poor communication among committee members & $1.7(0.8)$ & $1.9(0.9)$ & .110 \\
\hline Curriculum meetings are cancelled or disorganized ${ }^{c}$ & $1.4(0.9)$ & --- & $\mathrm{n} / \mathrm{a}$ \\
\hline Lack of student views or perspectives ${ }^{c}$ & $1.4(0.8)$ & --- & $\mathrm{n} / \mathrm{a}$ \\
\hline Public image is considered when making changes to the curriculum ${ }^{\mathrm{c}}$ & $1.4(0.8)$ & --- & $\mathrm{n} / \mathrm{a}$ \\
\hline
\end{tabular}

a. Five-point scale ranged from $1=$ not at all to $5=$ very high (barrier)

b. One participant did not rate barriers to committee effectiveness in 2020 survey

c. New item added for 2020 survey 
Table 4. Number (\%) of Committees Reporting Near Completion of Mapping these Standards in 2020

\begin{tabular}{lc}
\hline Standards 2016 CAPE domains & $\begin{array}{c}\text { Number (\%) } \\
\mathbf{n}=\mathbf{1 0 2}^{\mathbf{a}}\end{array}$ \\
\hline Standards 2016 CAPE domains & \\
Std 1 Foundational knowledge & $84(82)$ \\
Std 2 Patient-centered care & $79(78)$ \\
Std 2 Medication use systems management & $75(74)$ \\
Std 2 Health and wellness & $75(74)$ \\
Std 2 Population-based care & $73(72)$ \\
Std 3 Interprofessional education & $74(73)$ \\
Std 3 Problem solving and critical thinking & $74(73)$ \\
Std 3 Cultural sensitivity and awareness & $70(69)$ \\
Std 3 Communication and education & $76(75)$ \\
Std 4 Self-awareness & $72(71)$ \\
Std 4 Leadership & $74(73)$ \\
Std 4 Innovation and entrepreneurship & $68(67)$ \\
Std 4 Professionalism & $75(74)$ \\
Additional elements not in Standards 2016 & \\
Co-curricular activities and reflections & $59(58)$ \\
Pharmacist patient care process (PPCP) & $58(57)$ \\
Teamwork & $55(54)$ \\
\hline
\end{tabular}

CAPE $=$ Center for the Advancement of Pharmacy Education

Note: Std 3 Patient Advocacy was not evaluated in the survey; communication and education were evaluated as a combined item

a. Three curriculum committees did not provide responses for this question 


\begin{tabular}{|c|c|c|c|c|c|}
\hline & $\begin{array}{c}\text { Curriculum } \\
\text { Committee } \\
\text { Primary } \\
\end{array}$ & $\begin{array}{c}\text { Assessment } \\
\text { Committee } \\
\text { Primary } \\
\end{array}$ & $\begin{array}{c}\text { Committees } \\
\text { Share } \\
\text { Responsibility } \\
\text { (No Primary) }\end{array}$ & $\begin{array}{c}\text { Other } \\
\text { Entity Is } \\
\text { Primary } \\
\end{array}$ & $\begin{array}{c}\text { No } \\
\text { Response } \\
\text { Blank } \\
\end{array}$ \\
\hline Interprofessional education & $44(42)^{\mathrm{a}}$ & $6(6)$ & $40(38)$ & $14(13)$ & $1(1)$ \\
\hline Co-curriculum & $29(28)$ & $10(10)$ & $50(48)^{\mathrm{a}}$ & $14(13)$ & $2(2)$ \\
\hline EPAs & $23(22)$ & $17(16)$ & $38(36)^{a}$ & $21(20)$ & $6(6)$ \\
\hline APPE Readiness & $21(20)$ & $21(20)$ & $34(32)^{a}$ & $27(26)$ & $2(2)$ \\
\hline Student course/instructor evaluations & $16(15)$ & $32(30)$ & $45(43)^{\mathrm{a}}$ & $12(11)$ & $0(0)$ \\
\hline High stakes exams for progression & $14(13)$ & $33(31)^{a}$ & $32(30)$ & $14(13)$ & $12(11)$ \\
\hline NAPLEX / MPJE practice exams & $8(8)$ & $33(31)$ & $41(39)^{a}$ & $17(16)$ & $6(6)$ \\
\hline AACP Quality Surveys & $5(5)$ & $59(56)^{\mathrm{a}}$ & $26(25)$ & $13(12)$ & $2(2)$ \\
\hline PCOA & $5(5)$ & $61(58)^{a}$ & $23(22)$ & $15(14)$ & $1(1)$ \\
\hline Graduating Student Exit Surveys & $4(4)$ & $58(55)^{a}$ & $32(30)$ & $10(10)$ & $1(1)$ \\
\hline Licensing exams (NAPLEX, MPJE) & $3(3)$ & $46(44)^{\mathrm{a}}$ & $35(33)$ & $19(18)$ & $2(2)$ \\
\hline
\end{tabular}

a. Committee or entity with the highest percentage of primary responsibility is bolded

$\mathrm{EPA}=$ entrustable professional activities, APPE=advance pharmacy practice experience; NAPLEX=North American Pharmacy Licensure Examination; MPJE=Multistate Pharmacy Jurisprudence Examination; AACP=American Association of Colleges of Pharmacy;

PCOA $=$ Pharmacy Curriculum Outcomes Assessment 